On September 22, 1968, a total solar eclipse will be observed on the territory of the USSR. A full phase band will start near Severnaya Zemlya, North Land, will cross the Kara Sea and enter the mainland near Vorkuta. It will then go nearly straight to the south along the $62 \mathrm{nd}$ to the 64 th meridians. Then, turning sharply to the south-east, it will pass slightly north of Alma-Ata, west to west China and will end north of Lobnor Lake.

Although the 1968 eclipse is unfavourable for observations because of the short length of time for which it will be visible-a maximum of 42.7 seconds-and the low height of the Sun above the horizon-a maximum of $18 \cdot 7^{\circ}$-many Soviet astronomors are going to observe it. It is proposed to place nearly all expeditions near the railway station of Kargopolye, on the SverdlovskKurgan line, where the maximum duration of the eclipse and the maximum height of the Sun above the horizon are combined with relatively favourable meteorological conditions.

In the optical range, all traditional types of eclipse observations of the corona, chromosphere and photosphere will be conducted. Associates of the astrophysical observatory of the Georgian Academy of Sciences, as well as the astronomical observatories of Kiev, Lvov and Ural Universities, intend to obtain large-scale photographs of the inner, middle and outer coronas important for studying coronal structural details. Kiev and Lvov Universities are planning to observe the degree of polarization of coronal emission, while the observatory at Lvov will undertake colorimetric observations of the corona. The spectrum of the corona will be photographed by the Abactumani Astrophysical Observatory of the Georgian Academy of Sciences, and by the astronomical observatories of Kiev, Ural and Kharkov, as well as by the Sayanskaya Solar Observatory.

The observatory of Kharkov University is planning to take direct photographs of the chromosphere at the wavelength of the hydrogen $a$-line. The sun department of the Institute of Terrestrial Magnetism, the Sayanskaya Solar Observatory (with the Echellete spectrograph) and the main astronomical observatory of the Ukrainian Academy of Sciences are planning to study the chromospheric spectrum, which requires great skill in observations and subsequent thorough processing. The programme of the Sternberg Astronomical Institute includes taking pictures of the chromosphere and the corona with the Fabry-Perot standards which make it possible to evaluate the distribution of the temperature and the turbulence velocity around the solar disk.

In addition, the programme of the Sternberg Institute and the main observatory of the Ukrainian Academy of Sciences includes investigations of the photospheric spectrum on the solar limb, and the behaviour of spectral lines near the limb. Ural University will do similar studies using a stationary horizontal solar telescope. The Sternberg Institute will also be making photoelectric records of fluctuations from the centre of the disk to the limb in individual portions of the photospheric continuous spectrum.

Finally, the main astronomical observatory of the USSR Academy of Sciences and the observatories of Leningrad and Kiev Universities are preparing to record solar emission during the eclipse. These recordings will include investigations of the fine struc- ture of local sources of the slowly varying component of the solar emission at $4 \mathrm{~cm}$, and of the distribution of radio brightness of local sources on the Sun, and on the limb of the quiet sun. Investigations will also be made of the degree of inhomogeneity of the corona, and of the radio sizes of the solar disk in the centimetre wavelength range.

\section{Transport Arranged}

Tre Minister of Transport, Mrs Barbara Castle, seems now to have completed most of her planning for the development of transport in Britain in the years ahead. The last of four white papers on transport policy was published earlier this week, and deals with the organiza. tion of public transport (Cmnd 3481, HMSO, 3s. 9d.). The outstanding proposal among those contained in the White Paper is that responsibility for public transport systems should be transforred to public transport authorities set up in the various regions of the United Kingdom. On some occasions, this will mean that municipal buses are nationalized. Because most transport undertakings are at present in public ownership, however, the principal effect of the new proposal would be to transfer to regional authorities responsibility which is at present centred on the central transport commission.

Mrs Castle hopes that her plan will commend itself to those who argue that transport systems should be planned in such a way that they are closely integrated with city planning, and she is no doubt correct in that assessment. It is also reasonable that, if the regional transport authorities are to be subsidized, the injection of money should be used to pay for capital resources rather than for running costs. Some difficulties stand out, however. For one thing, there is no assurance that within the framework of the proposals now put forward it will be possible to find room for the kinds of technical developments in transport which are necessary in modern cities. Monorails may be out of fashion, but there is always a possibility that a regional transport authority would be more anxious to guard the sanctity of its existing stock of buses than to introduce small road transport vehicles, for example.

\section{American Industrial Research}

INDUSTRY in the United States seems to be playing a decreasingly important part as a performer of research and development. It still does the lion's share-70 per cent in 1965-but this represents a decline from the peak reached in 1957 , when 78 per ecnt of all research was done by industry. The growth in the industrial sector, 5 per cent between 1964 and 1965 , is the slowest of all. These figures, published by the National Science Foundation in a report called Basic Research, Applied Research and Development in Industry (US Government Printing Office, 65 cents), show that despite the change in emphasis, industry in the United States still does a greater proportion of the work than does industry in Britain. In 1964-65, British industry was doing about. 60 per cent of all research and development work.

The slower growth recorded by industry in the US seems to have been a consequence of a deceleration of federal support; industry's own contribution has continued to rise at the same rate for several years. 
Between 1953 and 1959 the federal contribution to industrial research expenditure increased sharply, and overtook the industrial contribution in 1956 . Since then the scales have begun to tip the other way. American industry in 1965 financed some 45 per cent of the research work which it carried out, while federal support made up the rest.

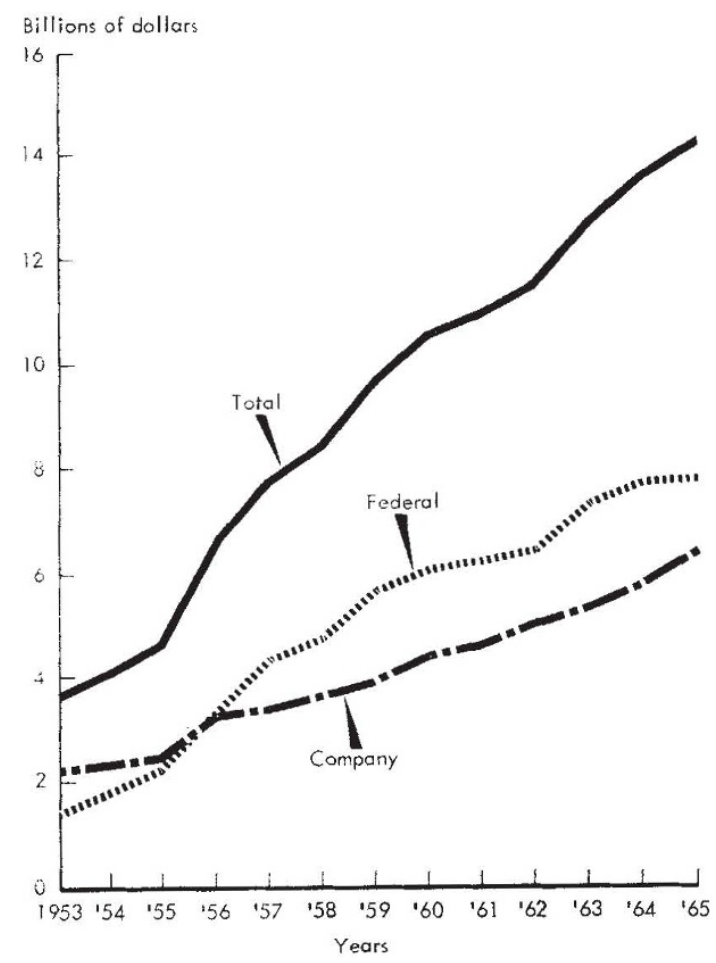

The changes in distribution are naturally over. shadowed by the sheer growth of research expenditure since 1953. Total expenditures have increased since then from $\$ 3,630$ million to $\$ 14,197$ million. Companies in the aircraft and missile business accounted for more than a third of this, some $\$ 5,120$ million, while research in the electrical equipment and com. munication business amounted to $\$ 3,167$ million. Just under 90 per cent of the aircraft and missile research was supported by federal funds, as was more than 60 per cent of the electrical and communication research. At the other end of the spectrum, the chemical and allied products industry found 85 per cent of its research expenditure from its own pocket.

Overwhelmingly the advantage lies with the big battalions. The eight companies with the largest research and development expenditures accounted for 11 per cent of net sales, 13 per cent of total employment, and 47 per cent of all federally supported research. There were some 13,400 companies conducting research in the United States in 1965 , but 87 per cent of the research was done by about 3 per cent of the companies. Among large companies, 29 had research and development programmes costing more than $\$ 100$ million and made up $\$ 9,000$ million of the total expenditure.

More than half the scientists and engineers working in industrial research worked in the aircraft, missile, electrical and communications industries. Together with chemicals and allied products, machinery, motor vehicles and other transport equipment, these industries employed 81 per cent of the qualified manpower. In January 1966, the total number of scientists and engineers employed in research and development was 358,900 .

\section{Monumental Masonry}

IN $1955 \mathrm{Mr}$ Michael Rix invented the name industrial archaeology. Although some say that industrial monuments are too recent to be considered archaeological relics, $\mathrm{Mr}$ Rix points out that an eighteenth century ironworks, the model $T$ Ford and the orystal set are really as out of date as a Stone Age axe. In a pamphlet called Industrial Archaeology, published by the Historical Association (3s. 6d.), Mr Rix makes a convincing case for industrial archaeology and, in particular, for preserving the monuments of the Industrial Revolution before it is too late. This is especially important in Britain, of course, where the Industrial Revolution began and where there are many of its relics.

The pamphlet makes encouraging reading, and the increase in the number of industrial museums, the founding of the journal Industrial Archaeology and the encouragement and indirect support of the Government point to the rapid expansion and interest in industrial archaeology. The most immediate problem is to assess the importance of sites and items. Nobody knows exactly what relics of the Industrial Revolution are still left scattered about the country. A national survey of industrial monuments is being made under the auspices of the Council for British Archaeology, which receives some support from the British Government. This survey is being co-ordinated by Mr Rex Wailes, who, before joining the Council for British Archaeology eighteen months ago, acted as a consultant to the Ministry of Public Building and Works. Mr Wailes collects information and presents proposals for the preservation of industrial monuments to the council. If they are agreed upon, the council makes representations to the Government asking for a preservation order.

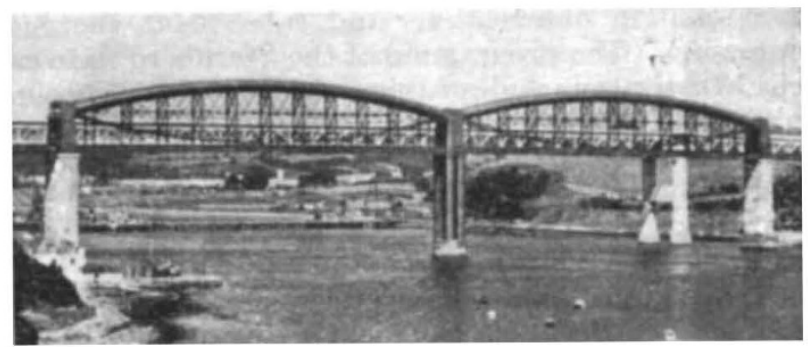

Railway bridge across the Saltash, built by I. K. Brunel for the Great Western Railway. The modern suspension bridge can be seen in the background. (British Rail photograph.)

At the same time, a national record of industrial monuments is being maintained at the Centre for the Study of the History of T'echnology at Bath University of Technology. But progress is slow and depends almost entirely on the work of individuals and local archaeology societies. In a progress report in the 